\title{
The clinic supervisory system as experienced by nurse supervisors
}

\author{
NM Tembani, (M.Cur), Department of Health, Bisho \\ D van Rooyen, (D.Cur), Department of Nursing Science, University of Port Elizabeth \\ J Strümpher, (D.Cur), Department of Nursing Science, University of Port Elizabeth
}

\section{Abstract}

A lack of proper monitoring and supervision of clinics in the King William's Town Health District (Eastern Cape) was highlighted by members of the public in the local newspaper, The Daily Dispatch, during 1999. A clinic audit conducted by the Health Information Unit of the King William's Town Health District further revealed the inadequacies of clinic supervision in this district. This article describes the qualitative study that was conducted with the aim of optimising clinic supervision in this health district. The study brought to light two issues that appear to be paramount in ensuring optimal clinic supervision. These are:

- The importance of formal and informal preparation of clinic supervisors for the supervisory role

- The support system that the clinic supervisors require to perform their duties effectively.

The focus of this article will be on the discussion of the research findings as well as guidelines that were developed to optimise clinic supervision.

\section{Opsomming}

Gedurende 1999 is die tekort aan effektiewe monitering en toesig in klinieke in die King William's Town Gesondheidsdistrik in die Daily Dispatch beklemtoon. ' $n$ Audit van sommige klinieke in die distrik deur die Gesondheidsinformasie Eenheid, het die tekortkominge van die kliniek toesig- en moniteringsisteem bevestig.

Die artikel beskryf ' $n$ kwalitatiewe studie wat onderneem is met die doel om die toesigsisteem in klinieke in genoemde distrik te optimaliseer. Die studie het die volgende twee punte wat van kardinale belang blyk om optimale toesig in klinieke te verseker, beklemtoon:

- Die belangrikheid van formele en informele voorbereiding van kliniekbestuurders vir hul rol

- Die ondersteuningsisteme wat die kliniekbestuurders benodig om hul take effektief te voltooi.

Die fokus van die artikel sal wees op die bespreking van navorsingsbevindinge en riglyne wat ontwikkel is om optimale toesig in klinieke te verseker.

\section{Introduction and background}

Three groups of supervisors are involved in the supervision of clinics in the King William's Town Health District. Their responsibilities are usually reflected in their job descriptions. The first level supervisor is the registered nurse in charge of a clinic. She/he is usually allocated to that clinic for a minimum period of 3 months. The second level supervisor is the area supervisor. She/he is a registered nurse with the rank of senior or chief professional nurse or nursing service manager and is stationed at a hospital. She/he is responsible for the supervision of a number of clinics. The supervisory functions of the first and second level supervisors are complementary and very similar, although the area supervisor is also expected to support the nurse in charge of the clinic in many ways, e.g. by updating her/him on changes and developments regarding policies and practices, assisting her/him with problem solving, facilitating the acquisition of the necessary skills and providing her/him with a written report after every visit. Such a report functions as feedback on the performance of the clinic staff and also highlights issues that need to be rectified in order to improve quality care.

The third group of supervisors are programme managers or coordinators from the District Health Office or Provincial Depart- ment of Health. They are responsible for monitoring the implementation of their specific programmes, e.g. a programme manager for mental health services would monitor mental health issues only when visiting a clinic. Each programme manager or provincial co-ordinator visits any clinic at any time to super vise her/his specific programme.

This study focuses on the first level clinic supervisor, i.e. the registered nurse in charge of a clinic

\section{Problem statement}

The Eastern Cape Department of Health formulated policy guidelines to ensure that all residents have access to health services. Some of the values encapsulated in the policy guidelines include service excellence, respect and concern for all patients and clients.

It appeared that this commitment by the Department of Health was not adhered to by the clinic staff in some of the clinics in the King William's Town Health District. Community members were being deprived of access to health care. This was indicated by the various complaints made by the public regarding a breakdown in services provided in the primary health care clinics in the King William's Town Health District. Complaints 
included non-availability of drugs at these clinics shortly after they had been delivered, a shortage of staff and delays in repairing equipment like baumanometers. The public attributed this situation to a lack of proper monitoring and supervision (Kene, 1998:8; Naki, 1998: 2 and Mpetile, 1998:6).

Complaints were also received regarding unprofessional behaviour of staff, e.g. reporting late for duty, unstaggered staff lunch breaks and pilfering medicines (Naki, 1999:2). The responsibility for monitoring these issues lies mainly with the nurse in charge of a clinic as the first level supervisor. The inadequacy of the clinic supervisory system was also highlighted by the findings of an audit of clinics conducted by the Health Information Unit of the King William's Town Health District. The audit highlighted high levels of absenteeism among nursing staff in the clinics of this district as a problem that needed to be addressed. The complaints forwarded by the public as well as the findings of the audit created the impression that nurses in charge of clinics in the King William's Town Health District were not performing their supervisory function effectively. This prompted the researcher to question how first level clinic supervisors in the King William's Town Health District experience their supervisory functions.

\section{Aim and objectives of the study}

The aim of the study was to optimise supervision of primary health care services in the King William's Town Health District. The objectives were threefold:

To explore and describe the experiences of first level clinic supervisors regarding their supervisory role;

To elicit the viewpoints of first level clinic supervisors about the strengths and weaknesses of the clinic supervisory system currently in use;

To develop guidelines that will optimise the clinic supervisory system used in the clinics in the King William's Town Health District.

\section{Research design \& method}

The study was based on a qualitative (Creswell, 1994: 161-162), exploratory, descriptive (Neuman, 1997: 19-20) and contextual design (Mouton \& Marais, 1994: 49).

\section{Research method}

The study was conducted in two phases:

PHASE 1: Entailed exploration and description of the ex periences of nurses in charge of the clinics regarding their supervisory role and the clinic supervisory system currently used.

PHASE 2: Described the guidelines that will assist nurse supervisors in their supervisory role and optimise the clinic supervisory system. The guidelines were based on the findings of Phase $I$ as well as on a literature control.

\section{Research population}

The research population consisted of registered nurses in charge of clinics in the King William's Town Health District. The criteria for inclusion in the sample were as follows: The participant must:

- Have worked as a registered nurse in charge of a particular clinic for at least one year;

- Be able to communicate in English;

- Be willing to participate.

\section{Sampling procedure}

Purposive sampling (Holloway \& Wheeler, 1998:75) was used to select the participants who would best address the research objectives.

\section{Data collection}

Unstructured interviews were held with seven first level clinic supervisors who met the selection criteria. The researcher felt that the data was saturated after seven interviews, as the same story- line seemed to appear from subsequent interviews. The interviews were tape-recorded and then transcribed verbatim. Field notes relating to the appearance of the clinic, non-verbal communication and the researcher's experience of the interview were kept, as well as a record of events. Ethical principles, as described by Polit \& Hungler (1997:130-138) were maintained throughout the study.

\section{Data analysis}

The database in this study consisted of transcribed interviews and field notes. In analysing the data, cognitive strategies that were used included inductive reasoning, synthesis, bracketing and intuition (De Vos, 1998: 336-337).

Categories or themes were identified by using Tesch's method of descriptive analysis (Creswell, 1994: 155). The raw data was sent to an independent coder with experience in qualitative research. A consensus discussion of the findings was held with the independent coder to identify the themes and subthemes

\section{Trustworthiness}

To ensure trustworthiness of the study, Guba's model (Krefting, 1991: 214-215) was used. This model specifically considers four aspects, including credibility, transferability, dependability and confirmability.

\section{Research findings and discussions}

All participants in this study were black females who had relevant experience, i.e. being in charge of clinics. The duration of the participants' employment as nurses in charge of clinics ranged from two to ten years. One of the participants was in charge of an urban clinic while six were in charge of rural clinics. Three participants in the study had post-basic qualifications in nursing management. 


\begin{tabular}{|c|c|c|c|}
\hline \multicolumn{2}{|c|}{ MAINTHFME } & \multicolumn{2}{|c|}{ SUB-THEMES } \\
\hline 1. & $\begin{array}{l}\text { Clinic supervisors experienced an in } \\
\text { ability to perform the supervisory func- } \\
\text { tion efficiently and effectively }\end{array}$ & $\begin{array}{l}1.1 \\
1.2 \\
1.3 \\
1.4\end{array}$ & $\begin{array}{l}\text { The nursing supervisors experienced role confusion related to their } \\
\text { supervisory function } \\
\text { Nursing supervisors felt inadequately prepared for the supervisory } \\
\text { role: } \\
\text { - No orientation on what and how to supervise } \\
\text { - Inadequate training relating to role expectations } \\
\text { A lack of resources interfered with the effective management of the } \\
\text { clinic: } \\
\text { - Shortage of staff } \\
\text { - Time constraints } \\
\text { A lack of transport to facilitate the performance of the supervi- } \\
\text { - Sory functions } \\
\text { A lack of autonomy made supervising difficult }\end{array}$ \\
\hline 2. & $\begin{array}{l}\text { Clinic supervisors experienced stress } \\
\text { as a result of being in charge of clinics. }\end{array}$ & $\begin{array}{l}2.1 \\
2.2 \\
2.3\end{array}$ & $\begin{array}{l}\text { The complex and challenging nature of the supervisory role evoked } \\
\text { stress } \\
\text { The attitude of colleagues caused supervisors to experience distress } \\
\text { The rotation allocation system caused supervisors to experience dis- } \\
\text { tress }\end{array}$ \\
\hline 3. & Support needs of clinic supervisors & 3.1 & $\begin{array}{l}\text { Visits of area supervisors as experienced by clinic supervisors } \\
\text { Staff development activities helped clinic supervisors to cope with } \\
\text { new situations and challenges } \\
\text { - In-service education } \\
\text { - Workshops } \\
\text { Coetings } \\
\text { supmunity participation in health matters gave support to the clinic } \\
\text { supers }\end{array}$ \\
\hline
\end{tabular}

A pilot study was also conducted to identify problems that might be encountered during the first phase.

Following a consensus discussion between the independent coder and the researcher, three main themes emerged from the participants' accounts of their experiences.

$\square \quad$ The first theme highlighted the inability of the first level clinic supervisors to perform the supervisory function efficiently and effectively

$\square \quad$ The second theme revealed that the first level clinic supervisors experienced their role as stressful

․ The third theme addressed the support needs of clinic supervisors

The themes and their sub-themes are depicted in Table 1.

The supervisory role of the first level supervisor is briefly described before the discussion of the themes and sub-themes. This role can be described as:

․ Setting goals for her/his clinic in consultation with the clinic staff and the district management team;

Assisting clinic staff in meeting those goals;

Ensuring the clinic is well staffed and well equipped; Identifying training needs, facilitating the training and; Monitoring the quality of service delivery.
Theme 1: Clinic supervisors experienced an inability to perform the supervisory function efficiently and effectively

The inability to perform the supervisory functions was perceived by the participants as emanating from the role confusion they experienced in the performance of their tasks, inadequate preparation for the supervisory role, a lack of resources and a lack of autonomy.

\section{Sub-theme: The nursing supervisors experienced role confusion related to their supervisory function.}

The participants said they had to perform supervisory functions as part of their duties. They explained that they were required to supervise all categories of clinic staff including nursing staff, the general assistants and gardeners. This entailed seeing to it that staff reported for duty punctually and went off duty at the correct time, motivating staff to work productively, identifying staff training needs and making the necessary arrangements for the provision of the relevant training. 
The participants also reported that they were required to supervise the provision of supplies to ensure an effective service. This involved acquiring and controlling medicines, ordering and repairing equipment and ordering and controlling surgical stock. Added to their managerial duties they also had to execute nursing duties like assessing patients, prescribing medication, dressing wounds and counselling.

"... I'm consulting, medication, dressings, I'm doing everything."

They were also involved with the community. This entailed home visits, organizing training of village health workers and clinic committees, providing health education in the clinic, in homes and in schools, assisting in establishing and implementing community health projects, assisting with training of student nurses allocated to the clinics and liaising with professionals in other disciplines to promote the health status of people in the community.

All participants in this study reported that they were unable to perform their supervisory duties as efficiently and effectively as expected. It became apparent during the interviews that the supervisors' time was devoted to direct patient care duties like patient consultations, prescribing medication and counselling clients rather than to supervision. The supervisors therefore felt that their supervisory duties were often neglected. This inability to perform supervisory duties was verbalized by one participant:

"It is a lack of identity as a supervisor because subordinates see you checking patients' blood pressure, testing urine, you know, checking vital signs. It is just you feel that as a supervisor, it's just a lip service in the sense that you don't do what you are saying. You don't implement it as a supervisor".

The statements made by the participants in this study indicate that the supervisory function was the least performed function by nurse supervisors. It was also noted that the supervisory function was not always reflected in the job description of the nurse in charge of the clinic and in two clinics job descriptions were not available.

\section{Sub-theme: Nursing supervisors felt inadequately prepared for the supervisory role}

Participants tended to feel that they were not adequately prepared for the supervisory role prior to placement in a supervisory position. No orientation on what and how to supervise was given. No arrangements were made for proper handing over from the person currently in charge of the clinic prior to placement in a clinic.

Inadequate training relating to role expectations was also mentioned as one of the factors that resulted in clinic supervisors failing to perform their supervisory function optimally. The participants expressed a need for formal training in order to be able to function effectively within their supervisory roles. They felt that nurses appointed in supervisory positions should be trained either in Community Nursing Science, Primary Health Care or Nursing Administration

Strasser (1998:2) supports the need for preparation for the supervisory role and recommends that the training needs of the clinic supervisors be determined. She warns about the danger of assuming that supervisors automatically have clinic and managerial expertise. She maintains that there is a need to establish the type of orientation required by, or provided to, new supervisors in a district and the way of addressing ongo- ing educational needs of supervisors. This point of view is emphasized by Dimond (1998:394) who advises that training must be provided for supervisors to ensure that they are well prepared for this role, as it cannot be assumed that supervision skills are innate.

\section{Sub-theme: A lack of resources interfered with the effective management of the clinic.}

All participants in the study indicated that inadequate resources especially personnel, transport, time, equipment and infrastructural resources hindered the efficient performance of the supervisory function. A shortage of staff forced nurses in charge of the clinics to devote most of their time on direct patient care duties and to pay less attention to supervisory duties. The participants in the study tended to express that they were unable to perform their supervisory duties because of time constraints. This was verbalized by one respondent:

"... Checking the work performance of your subordinates, identifying their strengths and weaknesses, the knowledge and skills that they have, the knowledge and skills that they lack - you don't have time to do it."

The participants also identified a lack of transport in order to facilitate effective execution of their supervisory functions as a problem. One of the roles that supervisors said they were expected to play was to oversee all health activities in the communities and do home visits. This requires transport, as some villages are quite distant from the clinic. Certain supervisors resorted to using their own cars to fetch medications or to attend workshops.

The participants also stated that a shortage of stock, equipment and infrastructural resources made supervision difficult. The shortage ranged from medical supplies and surgical stock to equipment, telephones and radiophones. This shortage was said to be interfering with the successful performance of the supervisory role.

\section{Sub-theme: A lack of autonomy made supervising difficult}

A lack of autonomy was perceived by the participants as interfering with decision-making and also as undermining the authority of the supervisors. Participants indicated that although they were given the responsibility of being in charge of the clinics, this was not coupled with authority to make independent decisions. They stated that they were expected to consult the area supervisors or community nursing service managers even for issues perceived by them as trivial.

\section{Theme 2: Clinic supervisors experienced stress at being in charge of clinics}

The majority of clinic supervisors who participated in this study experienced the supervisory role as evoking mild to moderate stress. Only one participant experienced the supervisory role as very, very stressful to the extent of causing mental exhaustion.

\section{Sub-theme: The complex and challenging nature of the supervisory role evoked stress}

The nurses in charge of clinics experienced their supervisory role as complex and challenging. This caused them to experi- 
ence elevated levels of stress. Two factors, namely a heavy workload and limited resources were experienced as the main stressors resulting in the complex and challenging nature of the supervisory role.

Another factor that was perceived as contributing to the stressful nature of the supervisory role was functioning within a challenging system characterized by staff shortages, a lack of transport as well as a lack of equipment, surgical stock and drugs.

Various methods have been suggested for the effective elimination of stress. One method is for managers to match the personal characteristics of their employees to the culture of the organization in such a way that the 'right people are placed in the right places'. Some studies in the field of nursing have also established that adequate resource allocation can considerably reduce the impact of stress, particularly when the workload of personnel is affected (Lundh, 1999: 950).

\section{Sub-theme: The attitude of colleagues caused the supervisors to experience distress}

Participants in this study tended to express concern about the attitudes of both area supervisors and subordinates, which were perceived as stressful. Area supervisors, or community matrons as they are sometimes called, were perceived as evoking stress due to the way they conducted supervision when visiting the clinics. The participants alleged that supervision was conducted like a policing or a faultfinding exercise.

Only two participants mentioned experiencing stress as a result of the attitude of their subordinates. Supervisors reported the difficulty they experienced in maintaining discipline amongst subordinates as the subordinates stated that they had a democratic right to do as they pleased. Supervisors also stated that they did not experience sufficient support from their managers in dealing with subordinates who displayed a negative attitude.

\section{Sub-theme: The rotation allocation system caused supervisors to experience distress}

The system of allocating clinic staff to one clinic for a specific period and then relocating her/him to another clinic or back to the hospital responsible for reallocation, was experienced as stressful by the participants in this study. This practice was said to be very demanding for the supervisor, as she/he had to keep on orienting new staff members to the clinic.

\section{Theme 3: Support needs of clinic supervisors}

Clinic visits by area supervisors, staff development activities including in-service education opportunities, workshops, meetings and community participation in health matters were activities in the present supervisory system identified by the supervisors as sources of support.

\section{Sub-theme: Visits of area supervisors as experienced by clinic supervisors}

Area supervisors were perceived as providing valuable support to the nurses in charge of clinics through their visits to the clinic. The nature of the support provided through clinic visits included updating clinic staff with information on changes in the health care delivery system, giving feedback on how clinic staff were performing their duties, giving assistance with problem-solving and conflict resolution and providing information on available continuing education opportunities.

The concept of conducting supervisory visits in order to provide the required support is strongly supported by Strasser (1998:3). Strasser suggests a need to provide onsite support when new programmes or practices are introduced, as well as ways to ensure effective use of clinic visits. She maintains that clinic visits have to be scheduled in a rational way, objectives for each visit determined, a checklist used, records of the visits kept and timely feedback be provided to the clinic staff.

One participant highlighted the fact that although she valued the area supervisor's visits, clinic visits were done in a hurried manner that did not give her sufficient time to discuss her problems with the area supervisor or to obtain the necessary support. This problem emanated from the fact that in order to visit the clinic, the area supervisor had to share transport with the community doctor and whilst the doctor saw patients, the area supervisor conducted supervision. Visits were hurried in order that the supervisor did not miss the transport back to the hospital.

\section{Sub-theme: Staff development activities helped clinic supervisors to cope with new situations and challenges}

Participants experienced the opportunity to attend in-service education opportunities, workshops, seminars, short courses and meetings as a strong source of support. Participants stated that they felt refreshed, updated and confident after attending these continuing education activities. Some participants had undertaken formal post registration courses in Community Nursing Science, Nursing Administration and Primary Health Care Nursing Science in order to empower themselves. Others had attended, or were attending, in-service education lectures or courses.

The monthly meetings that were held with area supervisors and other peers were also experienced as valuable since they afforded time to share problems encountered in the clinics and to realize that other supervisors were experiencing similar problems. Planning can be done jointly and the best solutions for identified problems sought.

\section{Sub-theme: Community participation in health matters gave support to the clinic supervisors}

Some of the participants stated that they were influential in organizing community members like village health workers, and setting up clinic committees to participate in health matters where these had not existed before. Participants also mentioned links that they had established with individuals from other fields or sectors to assist in addressing health problems. The supportive value of community participation did not only ease the work of clinic supervisors but also made it enjoyable.

\section{Guidelines to optimise the supervisory role of the first level clinic supervisor}

The following guidelines are based on the identified needs following analysis of the themes and the literature review. 
These guidelines have been generated to prepare and equip the first level supervisors for their supervisory responsibilities and to optimise clinic supervision.

\section{Develop a clear job description}

Job descriptions are useful for a number of purposes like giving an employee a clear picture of her/his responsibilities, assisting in the evaluation of job performance, assisting in the orientation of new employees to their jobs, forecasting training needs and showing the proper channels of communication (Booyens, 1998:232-233).

Strasser (1998: 23) alludes to the fact that one of the difficulties experienced by participants in the position of clinic supervisor is the lack of a clear job description resulting in more time being spent on non-supervisory tasks. It is important to determine how the scope of responsibilities of a clinic supervisor differs from that of a programme manager and programme co-ordinator, and how the expectations for, and responsibilities of, coordinators and programme managers complement or overlap one another. The job description should indicate the supervisory duties of the nurse in charge of a clinic as a first level supervisor regarding utilization or allocation of resources such as the budget, staff, availability of water, electricity, equipment and supplies like drugs, cleaning materials, stationery and maintenance of the clinic building. The job description should also indicate how the first level clinic supervisor is expected to interact with the communities, organizations and the government departments that support service provision.

\section{Set selection criteria for the position of first level \\ Supervisor}

The criteria for appointment as a supervisor should be defined and these criteria must include relevant experience, qualifications, knowledge base and personal attributes. The supervisor should have some experience in supervision and have consolidated that experience, although the length of experience or seniority does not necessarily correlate with effective supervision (Fowler, 1995:36). The supervisor should demonstrate knowledge and skills in the area that she/he is supervising. One measure of this may be the successful completion of a formally recognized relevant course, e.g. a Diploma in Nursing Management (Fowler, 1995:36).

\section{Delegate responsibility and authority}

The current situation of clinic supervision as experienced by first level supervisors is that they are given the responsibility of being in charge of a clinic without the associated authority. They perceive this situation as weakening their confidence and ability to supervise and diminishing their power to exercise control over their subordinates. They interpret their position as tantamount to being a contact person. Delegation of responsibility and authority will assist in removing over-reliance on area managers who in most cases visit the clinic once a month, or sometimes never due to transport problems. The first level supervisors need to be given an opportunity to develop their problem-solving and decision-making skills. It is important however that they are equipped with the necessary knowledge and skills to perform these tasks competently.

\section{Develop an orientation programme for clinic supervisors}

The orientation programme should at least address the job requirements and job expectations, the daily, weekly and monthly duties, the physical layout of the nursing unit and communication channels and structures. Formal introduction of the newly appointed supervisor to the clinic staff, clinic committee and the community members is essential in order to foster acceptance and to ease the functioning of the clinic supervisor.

There should also be proper transfer of authority from the person vacating the post to the new registered nurse who will take charge of the clinic.

\section{Formal preparation for the supervisory role}

Although needs will vary from district to district, clinic supervisors should at least have strong skills in primary clinical care, health promotion, good interpersonal skills as well as the ability to supervise and mentor (Strasser, 1998:2). A prospective clinic supervisor can act as understudy to an experienced clinic supervisor for a fixed period of time in order to learn the realities of the job and to build confidence. Attendance at staff development opportunities should be implemented in a structured manner guided by training needs.

\section{Provision of support}

The necessary supervisory tools and resources that will facilitate the supervisor's functioning and increase the effectiveness of clinic supervision should be provided in order to support the first level supervisors. The relevant supervisory tools with which the nurse in charge of a clinic should be provided are supervisory checklists, a handbook for clinic managers outlining clinic functions and policies, performance appraisal tools and treatment guides and protocols. Providing resources such as transport, staff, equipment and means of communication, will improve the supervisor's ability to function in her/his role and promote clinic supervision.

\section{Designing a long-term clinic rotation plan}

Clinic supervisors and their subordinates need prior notification regarding their allocation to another clinic or back to the hospital. It is therefore recommended that a long-term clinic rotation plan be designed. The plan must be sufficiently flexible to take special requests into account and it should be reviewed annually. This move will minimize stress caused by a need to continually orientate and arrange training for new staff. 
Disorganization of family life and the interruption of projects that have been initiated by the supervisor and clinic staff will be averted if rotation is done in a well-planned and proactive manner.

\section{Conducting annual review of the training needs of first level supervisors}

Supervisors themselves require periodic training and updates to remain abreast of the many rapid changes in health care, e.g. the changing health policies, changing professional legislation and advances in health technology. The value of in-service training in these circumstances cannot be overemphasized. Some of the topics that can be included in an in-service education programme for clinic nurses are:

$\square \quad$ Resource planning and management, including budget planning and human resource planning and development

Time management

Stress management

Labour relations

Identification and utilization of support systems (intersectoral collaboration).

\section{Limitations of the study}

$\square$ Due to the rural nature of the King William's Town district, more rural than urban clinics were represented in the study.

$\square \quad$ Cultural and gender representation could not be achieved as was initially planned by the researcher because none of the clinics were supervised by male registered nurses. The only white female clinic supervisor who could have participated in the study withdrew on the day of the interview because of an urgent assignment.

Clinics that were furthest from the provincial and district offices and from the supervising hospitals were not represented, as they were not accessible to the researcher due to the conditions of the roads.

The study was conducted at a time when rearrangement of clinic supervision was being considered.

\section{Recommendations}

The recommendations are made with specific reference to nursing practice, nursing education and nursing research

\section{Nursing practice}

The position of the nurse in charge of a clinic as first level supervisor needs to be upgraded to that of a senior or chief professional nurse depending on the size of the clinic. This will place her/him at the same level as her/his counterparts in a hospital ward or unit. The first level clinic supervisor should be relieved of other duties such as direct patient care duties, in order that she/he can monitor, evaluate and oversee all activities in her/his clinic with the guidance of the supervisory checklists and handbooks for managers that are presently used by area supervisors. This recognition of status for the first level supervisor will increase her/his authority and confidence and enable her/him to exercise more direct control over her/his subordinates. This will prevent her/him from contributing to the problems in the clinic.

Optimal supervision will be achieved by shifting the focus to direct energies into equipping the nurse in charge of a clinic with supervisory skills rather than concentrating on the area supervisors as is current practice. The present over-reliance on "strangers" who visit the clinic once a month can result in a dependency situation and abuse of area supervisors. Some problems, such as those relating to staff discipline, are sometimes postponed for the attention of the area supervisor when she/he visits the clinic without making an earnest effort to resolve them. An investment in the nurses in charge of the clinics and a re-evaluation of their role to allow them to function optimally is clearly needed.

\section{Nursing education}

The research results revealed the supportive value of staff development programmes. A needs analysis should be conducted annually in all clinics and the information channelled to the In-Service Education Committee. A policy should be formulated recommending that each clinic supervisor attend at least two continuing education activities per year. The present clinic supervisory manuals and checklists have to be reviewed to determine their relevance to the current health care situation.

\section{Nursing research}

This study has revealed that staff development activities like in-service education and workshops are experienced as supportive by clinic supervisors, but further research is needed to evaluate the impact of such continuing education activities on client or customer satisfaction.

\section{Conclusions of the study}

The results of the interviews, as well as the field notes, highlighted the fact that clinic supervisors experienced an inability to perform their supervisory function effectively and efficiently. A lack of resources and autonomy, role confusion and inadequate preparation for the supervisory role were cited as undermining the capacity of first level clinic supervisors to perform their supervisory duties. These were the weaknesses that need to be addressed or improved in the present clinic supervisory system. The supervisors also perceived their supervisory role as stressful but felt supported by those area supervisors who used clinic visits constructively. Participants also suggested that attending in-service education programmes, workshops and meetings offered further beneficial support. Community members and community health structures like clinic committees were also perceived as providing the first level clinic supervisors with necessary support. The supportive elements or activities were perceived as the main strengths of the present clinic supervisory system. The guidelines that were designed are to assess and address the support needs of supervisors of clinics. 


\section{Bibliography}

BOOYENS, SW (ed) 1998: Dimensions of Nursing Management. $2^{\text {nd }}$ edition. Cape Town. Juta \& Company Ltd.

CRESWELL, JW 1994: Research Design. Qualitative and Quantitative Approaches. London: Sage Publications.

DE VOS, AS 1998: Research at Grassroots - a primer for the caring professional. Pretoria: Van Schaik

DIMOND, B 1998: Legal Aspects of clinical supervision 1: employer vs employee. British Journal of Nursing. 7(7): 393-395.

EASTERN CAPE DEPARTMENT OF HEALTH 1999: Strategic Health Care Plan 1999- 2003. Unpublished.

FOWLER, J 1995: Nurses' perceptions of the elements of good supervision. Nursing Times. 91(22): 33-37.

HOLLOWAY, I \& WHEELER, S 1998: Qualitative Research for Nurses. Cornwall: MPG Books Ltd.

KENE, S 1998: Nurses urge the EC government to improve clinics. Daily Dispatch, 1 December: 8.

KREFTING, L 1991: Rigor in qualitative research. The assessment of trustworthiness. The American Journal of Occupational Nurses. 45(3) 214-219.

LUNDH, U 1999: Job satisfaction among Swedish nurses and laboratory technology. British Journal of Nursing. 8(14): 948-952.

MOUTON, J \& MARAIS, H 1994: Basic concepts in the methodology of the social sciences. Pretoria. Human Sciences Research Council.

MPETILE,J 1998: Sick of MEC's excuses. Daily Dispatch, 24 December: 6 .

NAKI, E 1998: Poor controls cause EC medicine shortage. Daily Dispatch, 10 December: 2.

NAKI, E 1999: Nurse due to appear in court for theft of drugs. Daily Dispatch, 28 May: 2.

NEUMAN, WL 1997: Social research methods. Qualitative and Quantitative Approaches. $3^{\text {rd }}$ edition. London: Allyn and Bacon.

POLIT, DF \& HUNGLER, BP 1997: Essentials of Nursing Research Methods, Appraisal and Utilization. Philadelphia: Lippincott.

STRASSER, S 1998: Support staff through effective supervision. How to assess, plan and implement more effective clinic supervision. Initiative for Sub-District Support. Durban: Health Systems Trust. 